\title{
Transformation of $M / A$ Constituents during Tempering and Its Effects on Impact Toughness of Weld Metals for X80 Hot Bends
}

\author{
Gui-ying Qiao, ${ }^{1,2,3}$ Xiu-lin Han, ${ }^{4}$ Xiao-wei Chen, ${ }^{4}$ Xu Wang, ${ }^{4}$ Bo Liao, ${ }^{2,3}$ \\ and Fu-ren Xiao $\mathbb{D i D}^{2,3}$ \\ ${ }^{1}$ Key Lab of Applied Chemistry of Hebei Province, School of Environment and Chemical Engineering, Yanshan University, \\ Qinhuangdao 066004, China \\ ${ }^{2}$ Key Laboratory of Metastable Materials Science \& Technology, College of Materials Science \& Engineering, Yanshan University, \\ Qinhuangdao 066004, China \\ ${ }^{3}$ Hebei Key Lab for Optimizing Metal Product Technology and Performance, College of Materials Science \& Engineering, \\ Yanshan University, Qinhuangdao 066004, China \\ ${ }^{4}$ CNPC Bohai Petroleum Equipment Manufacture Co., Ltd., Qingxian 062658, China
}

Correspondence should be addressed to Fu-ren Xiao; frxiao@ysu.edu.cn

Received 29 March 2019; Revised 2 May 2019; Accepted 7 July 2019; Published 17 July 2019

Guest Editor: Antonello Astarita

Copyright (C) 2019 Gui-ying Qiao et al. This is an open access article distributed under the Creative Commons Attribution License, which permits unrestricted use, distribution, and reproduction in any medium, provided the original work is properly cited.

\begin{abstract}
Impact toughness of the weld metal is one of the important factors affecting the quality of hot bends, which is strongly dependent on the microstructure transformation during hot bending and tempering. In this study, three kinds of weld metals with different $\mathrm{Ni}$ contents were selected, and then the effects of tempering temperature on the microstructure impact toughness of weld metals for hot bends were investigated by simulation conducted on a Gleeble-3500 thermal simulator. The results show that the nonmetallic inclusion particles in weld metals can become the nuclear core of acicular ferrite like in as-welded metal. So, the overlapping acicular ferrite microstructure is obtained in the weld metal after direct cooling from the reheating temperature. During tempering, the overlapping acicular ferrite microstructure is degenerated, and martensite/austenite (M/A) constituents in the acicular ferrite microstructure decompose into ferrites and carbides. The resulting carbide particles mainly distribute along the acicular ferrite grain boundaries. With the increase of the tempering temperature, the carbide particles coarsen, which decreases the impact toughness of the weld metal of hot bends. Addition of Ni to weld metals can refine the acicular ferrite and improve the impact toughness.
\end{abstract}

\section{Introduction}

Bends are some of key parts of the pipeline projects $[1,2]$. Recently, in order to maximize the transport efficiency and decrease the construction and transposition costs, the gas pipeline transmission develops toward a larger diameter and/ or higher operation pressure; thereby, the high strength X80 steel grade and heavy-wall pipe over $22 \mathrm{~mm}$ have been applied to many long-distance transmission pipeline projects $[3,4]$, such as the Third West-to-East Gas Transmission Pipeline Project and the Sino-Russian Gas Transmission Pipeline Project. Contemporaneously, heavy-wall hot bends have been developed. The heavy-wall hot bends are usually made from longitudinal-seam submerged arc welding (LSAW) steel pipes by hot induction heated bending, on-line water cooling, and off-line tempering [5-7]. The microstructure and mechanical properties of the weld seam of LSAW steel pipes are different to the pipe body, and the acicular ferrite is obtained as an optimal microstructure to improve the impact toughness $[8,9]$. And yet for all that, the weld metal still has lower impact toughness than the pipe body. During the hot bending processes, the weld seam does not go through the bending deformation; nevertheless, the weld metal must undergo reheating, spraying water cooling, and tempering $[1,2,5-7]$. Accordingly, the effects of the reheating, water cooling, and tempering associated with the hot bending processes on impact toughness of the weld metal must be firstly considered. 
The hot bending processes including reheating, water cooling, and tempering for the weld metal are similar to the postwar heat treatment (PWHT) of quenching and tempering. It is well known that heat treatment is an effective method to improve the comprehensive mechanical properties of base materials and the weld joints [10-12]; especially, the impact toughness and strength of pipeline steels will be improved with the increase of the tempering temperature $[10,11]$. However, our previous works showed that the impact toughness of weld seam metals seems to decrease trends with the increase of tempering temperature for the X80 heavy-wall hot bends [13]. The similar results were found in high-strength pipeline steel. Slater and Wilkinson [14] reported that there is no significant effect of tempering on the Charpy toughness of the L450MB weld seam. However, tempering has a deleterious effect on the toughness of the L555MB weld seam. These results are contrary to the general rule of the effect of tempering on the toughness of the pipeline steels [10]. The difference between the weld metal and the pipeline steel may be attributed to that weld metal has acicular ferrite as-weld microstructure after the bending reheating and water cooling [11]. In addition, the alloying elements have a significant effect on the acicular ferrite transformation [8]. The high-strength steels and heavy-wall steel pipes have the higher amount of alloying elements, which promote the acicular ferrite transformation and increase the amount of acicular ferrite in weld metals [8]. It is well known that the original microstructure significantly influences the tempering microstructure transformation and mechanical properties after tempering. Therefore, the deteriorative effects of the tempering on impact toughness of the weld metal may depend on the transformation of the acicular ferrite. For improving the impact toughness of the weld metal of heavy-wall X80 hot bends, it is necessary to further reveal the microstructure of acicular ferrite and its transformation during tempering.

In this work, the effects of the main hot bending parameters of tempering temperatures on the microstructures and impact toughness of the three weld metals for heavywall grade X80 hot bends were investigated. Furthermore, the evolution of the microstructure and its effects on the toughness are discussed. The results will be beneficial to improve the impact toughness of weld metals of the grade X80 hot bends.

\section{Experimental Materials and Procedures}

In order to prove the universality of the experiment results, one kind of $\phi 1219 \times 25.6 \mathrm{~mm}$ X80 weld pipe and two kinds of $\phi 1219 \times 30.8 \mathrm{~mm}$ X80 weld pipes for hot bends were selected. The X80 weld pipe was manufactured by JCOE (J-shape, C-shape, O-shape, and E-expending) forming processes and double-face four-wire tandem submerged arc welding. The chemical compositions of the outside weld metals are shown in Table 1. The main difference in the chemical compositions of the weld metals of hot bends is the amount of Ni, which increases from $0.16 \%$ to $0.52 \%$.

Simulated bending test pieces of weld metals of size $10.1 \mathrm{~mm} \times 10.1 \mathrm{~mm} \times 80 \mathrm{~mm}$ were cut from cross outside weld joints, as shown in Figure 1. The simulating hot bending processes were performed on a Gleeble-3500 thermal simulator, and the process parameters are as follows: the heating time from room temperature to the reheating temperature $\left(990^{\circ} \mathrm{C}\right)$ was about $60 \mathrm{~s}$, and then the specimens were held above $60 \mathrm{~s}$ at the same temperature, and then cooled to room temperature with a cooling rate of $10^{\circ} \mathrm{Cs}^{-1}$. The cooling rate was approximated to the practical spraying water cooling rate during hot bending manufacturing. The tempering tests were conducted in a resistance furnace, and the tempering temperature was at $480 \sim 680^{\circ} \mathrm{C}$ for $1 \mathrm{~h}$.

After tempering, the simulated specimens were machined to Charpy impact specimens. The low-temperature impact energy was measured at $-40^{\circ} \mathrm{C}$. The microstructure observation specimens were cut from the impact specimens. The microstructure of the specimens was examined by using an optical microscope (OM), a KYKY-2800 scanning electron microscope (SEM) with Oxford-HKL electron backscatter diffraction (EBSD), and a JEM-2010 transmission electron microscope (TEM).

\section{Results}

3.1. Microstructure and Charpy Impact Toughness after Reheating and Cooling. Typical optical microstructures of the as-welded weld metal of the pipe for Bend A are shown in Figure 2(a). The microstructure of weld metals mainly consists of acicular ferrite and a few proeutectoid ferrite, and the ferrites mainly distribute along coarse prior austenite grain boundaries, as shown in Figure 2(a). The acicular ferrite is considered an optimal microstructure to improve the impact toughness of the weld metal. Increasing the amount of alloying elements will benefit to promote the acicular ferrite transformation for heavy-wall welded pipes with high weld heat input $[8,15]$. Hence, high Charpy impact energy of $146 \mathrm{~J}, 142 \mathrm{~J}$, and $153 \mathrm{~J}$ of the base pipes for Bend $\mathrm{A}$ to Bend $\mathrm{C}$ is obtained.

After simulated bending reheating and cooling, the microstructures of all steels are similar to the as-welded metal, while the coarse prior austenite grain boundaries disappear, as shown in Figures 2(b)-2(d). The microstructures consist of acicular ferrite and few polygonal ferrite aswelded microstructures. The acicular ferrite is needle-like shape and the acicular ferrite grains are overlapping each other; meanwhile, some dot-like islands distribute between the acicular ferrite grains. However, the Ni content strongly affects the amount and form of acicular ferrite and polygonal ferrite. As the Ni content in weld metal is at $0.16 \%$ (Table 1 ) for Bend A, the large-size polygonal ferrite and massive ferrite appear in the microstructure, and the acicular ferrite and islands are coarse (Figure 2(b)). With the increase of $\mathrm{Ni}$ content in weld metals (Table 1), the amount of large-size polygonal ferrite and massive ferrite decreases. The amount of acicular ferrite increases; meanwhile, the acicular ferrite is refined (Figures 2(c) and 2(d)). Figure 3 shows the inverse pole figure and boundary misorientation maps obtained from EBSD measurements for Bend C. From Figure 3(a), the acicular ferrite grains mainly appear in nonequiaxed shapes, and some small-angle grain boundaries are observed in large acicular 
TABLE 1: Chemical composition of the weld metal for hot bends (wt.\%).

\begin{tabular}{lccccccrrrr}
\hline Hot bends & $\mathrm{C}$ & $\mathrm{Si}$ & $\mathrm{Mn}$ & $\mathrm{P}$ & $\mathrm{S}$ & $\mathrm{Ni}$ & $\mathrm{Cr}+\mathrm{Mo}+\mathrm{Cu}$ & $\mathrm{Ti}$ & $\mathrm{Nb}$ & $\mathrm{V}$ \\
\hline Bend A & 0.07 & 0.27 & 1.60 & 0.010 & 0.004 & 0.16 & 0.41 & 0.016 & 0.032 & 0.03 \\
Bend B & 0.06 & 0.29 & 1.67 & 0.016 & 0.004 & 0.31 & 0.37 & 0.016 & 0.034 & 0.01 \\
Bend C & 0.06 & 0.28 & 1.67 & 0.019 & 0.005 & 0.52 & 0.39 & 0.015 & 0.036 & 0.01 \\
\hline
\end{tabular}

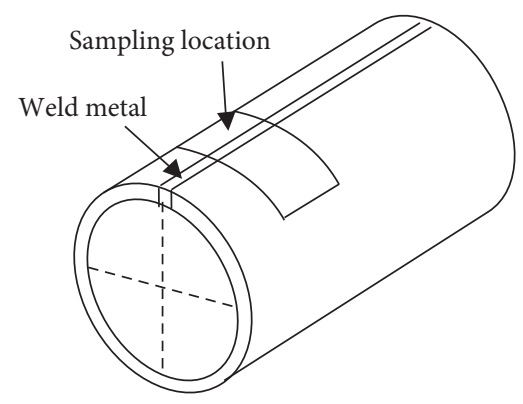

(a)

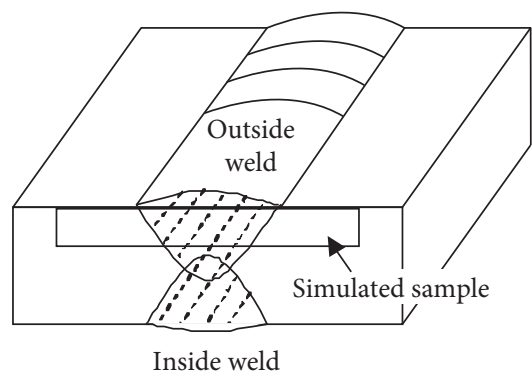

(b)

FiguRE 1: Sketch illustration of the sampling locations cut from the (a) welded pipe and (b) the weld metal.

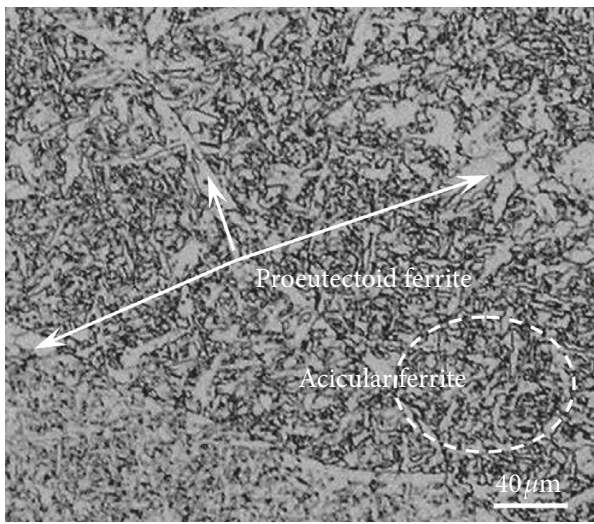

(a)

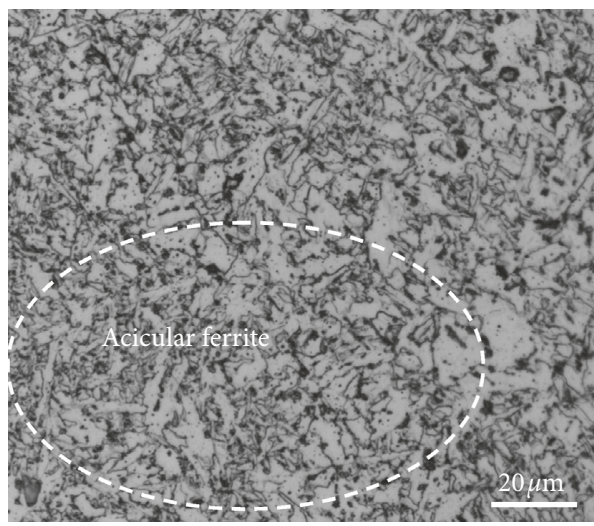

(c)

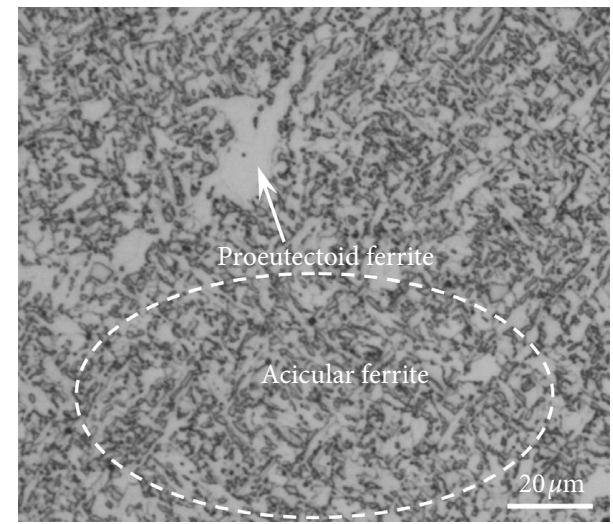

(b)

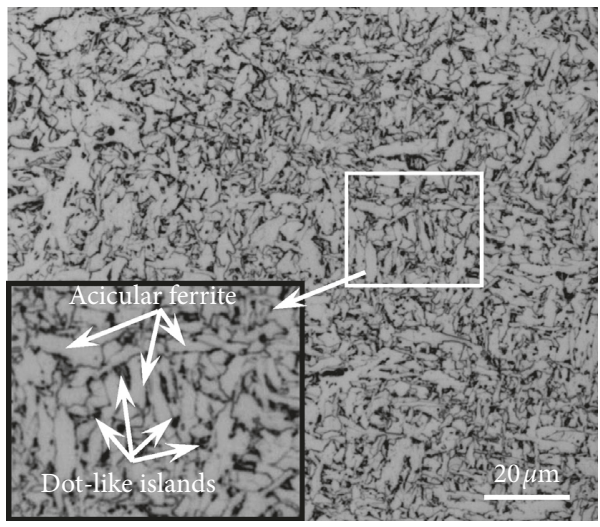

(d)

Figure 2: Optical microstructures of the weld metal and after reheating at $990^{\circ} \mathrm{C}$ : (a) Steel A as-weld; (b) Steel A reheating; (c) Steel B reheating; (d) Steel C reheating.

ferrite grains, which are clearly shown in Figure 3(b). The acicular ferrite microstructure mainly consists of the largeangle grain boundaries. Hence, with the increase of Ni content in weld metals, the amount of acicular ferrite increases and the microstructure of acicular ferrite refines (Figure 2). As a result, the Charpy impact energy increases. The average values of impact energy of weld metals for three bends from A to C are $65 \mathrm{~J}, 78 \mathrm{~J}$, and $114 \mathrm{~J}$, respectively.

The SEM and TEM observations show that the acicular ferrite nucleates around nonmetallic partials in the austenite grain and grows in all directions $[16,17]$, as shown in Figure 4. The nonmetallic partials are mainly $\mathrm{Ti}$-oxide (Figure 4(a)), 


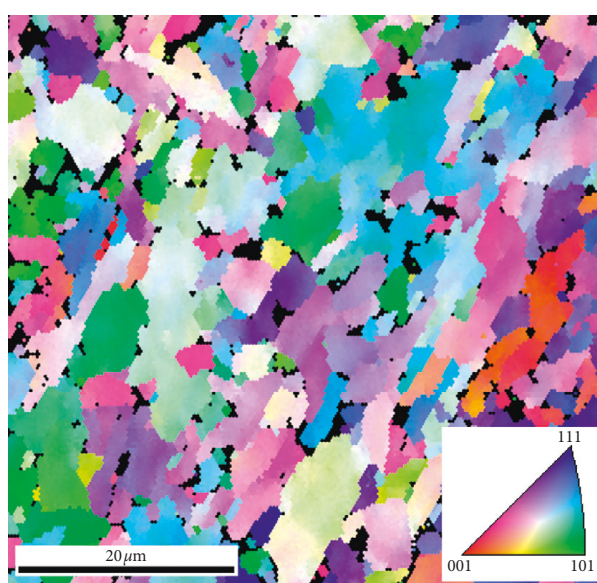

(a)

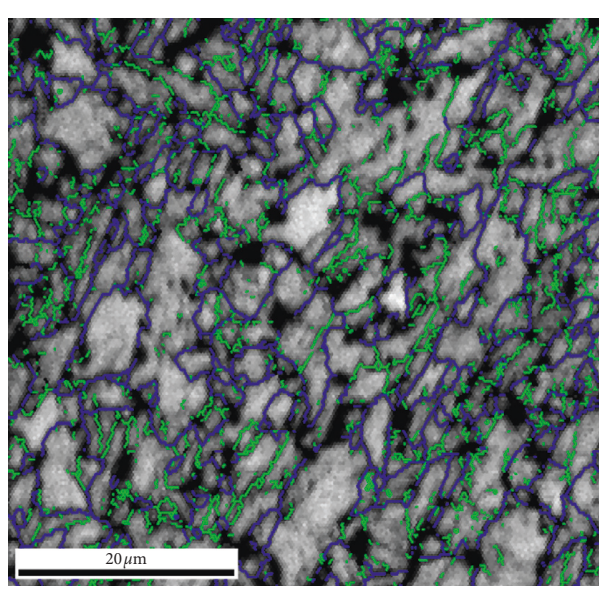

(b)

FIgURE 3: (a) Inverse pole figures and (b) boundary misorientation maps of the ferrite phase and phase distribution maps obtained from EBSD measurement of Bend C.

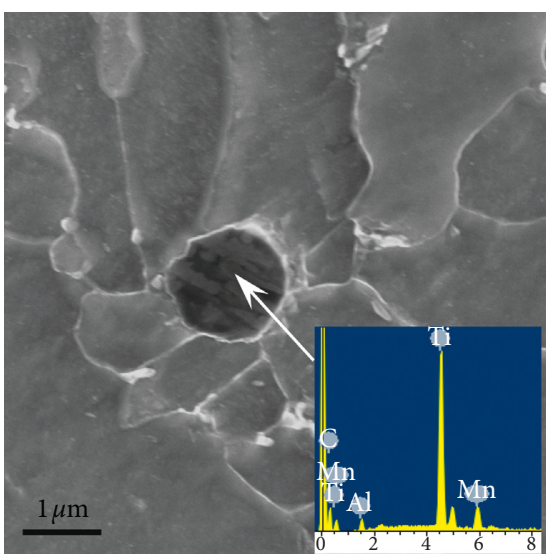

(a)

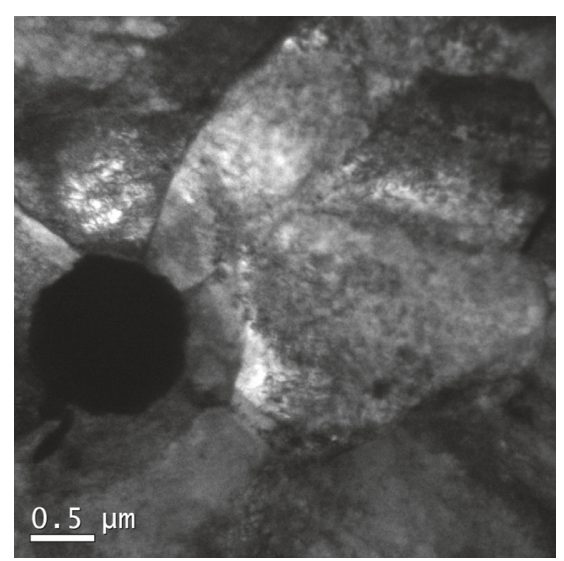

(b)

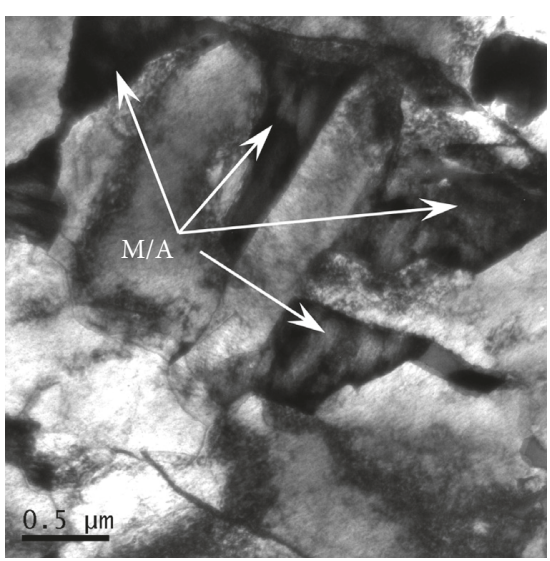

(c)

FIGURE 4: Acicular ferrite nucleated surrounding the nonmetallic oxide inclusion and M/A constituents in the microstructure: (a) SEM; (b) TEM; (c) M/A constituents.

which as heterogeneous nuclei promotes acicular ferrite nucleation (Figures 4(a) and 4(b)); as a result, the overlapping acicular ferrite with needle-like shape forms (Figures 2, 4(a), and 4(b)). Meanwhile, some dot-like island constituents distribute on ferrite grain boundaries (Figure 4(c)), which are denoted as martensite/austenite (M/A) constituents in the low-carbon microalloying steel fields $[8,9]$. The specific microstructure will affect the tempering transformation and its mechanical properties after the tempering.

3.2. Effect of Tempering on Impact Toughness. The effect of the tempering temperature on impact energies of weld metals is shown in Figure 5. Comparing with the samples after simulated bending reheating and cooling, the impact toughness is improved when tempering is at lower tempering temperature of $480^{\circ} \mathrm{C}$. However, as the tempering temperature further increases, the impact energy of all

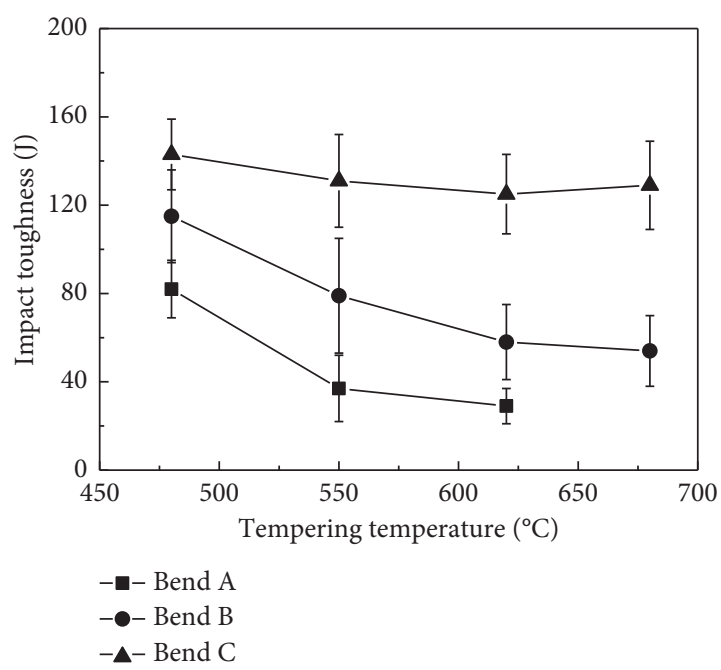

Figure 5: Effect of tempering on the Charpy impact energy. 
specimens for hot bends decreases (Figure 5). The results are different from the common rule of the steels that the tempering improves the impact toughness. The change of impact toughness with the tempering temperatures of weld metals may be attributed to the difference in the microstructure and its changes during tempering. In addition, from Figure 5, Bend A with low Ni content has lower Charpy impact energy, while Bend $\mathrm{C}$ with high Ni content has higher Charpy impact energy. The above results suggest that addition of $\mathrm{Ni}$ and tempering at a lower temperature can improve the low-temperature impact energy of weld metals of the hot bends.

\subsection{Transformation of the Acicular Ferrite during Tempering.} The microstructures of the weld metals of hot bends after tempering are shown in Figure 6. At the low tempering temperature, the microstructures of all weld metals still maintain the microstructure characteristic of acicular ferrite after simulated hot bending and cooling, which are a mixture of acicular ferrite, polygonal ferrite, and M/A constituents (Figures 6(a), 6(d), and 6(g)). With the increase of the tempering temperature, the microstructure changes slightly. The variation only appears when the amount of large massive ferrite increases, which indicates that some acicular ferrites degenerate (Figures 6(b), 6(c), 6(e), 6(f), 6(h), and 6(i)). However, the transformation of M/A, which works as a significant constituent in the acicular ferrite, cannot clearly be observed by the optical metallography (Figure 6). Thus, SEM and TEM have been used, and the microstructural variation of selected typical specimens is shown in Figures 7 and 8 .

Figures 7 and 8 show the SEM microstructures of Bend C after tempering at different temperatures. As the tempering temperature is at $550^{\circ} \mathrm{C}$, the ferrite matrix and some $\mathrm{M} / \mathrm{A}$ constituents change a little, while some M/A constituents begin to degrade (Figure 7(a)). The M/A constituents decompose into carbides and ferrites, and the carbides appear in fine rod-like shapes (Figures $8(\mathrm{a})$ and $8(\mathrm{~b})$ ). With the increase of the tempering temperature, some acicular ferrites begin to coarsen; meanwhile, the carbides change to spheroid and distribute along the ferrite grain boundary (Figures 7(b) and 7(c); Figures 8(c)-8(f)). Simultaneously, some large M/A constituents decompose into ferrite and spheroid carbides, and the carbides distribute in the ferrite grain (Figures $8(\mathrm{~d})-8(\mathrm{f})$ ).

The EBSD pole figures and boundary of the misorientation maps of the ferrite phase and the phase distribution maps obtained from the EBSD measurement of the specimens of Steel C after tempering at different temperatures are shown in Figure 9. Comparing with Figure 3, at low tempering temperature, the microstructure changes little. The microstructure is a mixture of large massive ferrite grain and fine nonequiaxed acicular ferrite (Figure 9(a)). The boundaries between the acicular ferrite grains are mainly high-angle grain boundary $\left(\theta \geq 15^{\circ}\right)$. The fraction of highangle grain boundary is 0.573 , and the fraction of low-angle grain boundary $\left(2^{\circ} \leq \theta \leq 15^{\circ}\right)$ is 0.158 (Figure $9(\mathrm{~b})$ ). At the same time, the M/A constituents do not fully disintegrate; some retained austenite exists in the microstructure (Figure 9(c)). As the tempering temperature rises to $620^{\circ} \mathrm{C}$, the ferrite grains appear with the fragmentation phenomenon, and some refined grains with high-angle and/or low-angle boundaries can be found in the pole figure (Figure 9(d)) and boundary misorientation map (Figure 9(e)). Meanwhile, the M/A constituents almost fully disintegrate, and some refined carbide clusters are found on the boundaries and/or in the corner of ferrite grains (Figure 9(f)). The microstructural transformation mainly ascribes the decomposition of M/A, as well as the recovery and recrystallization of the acicular ferrite. With the further increase of the tempering temperature to $680^{\circ} \mathrm{C}$, some acicular ferrite grains coarsen (Figure 9(g)). Moreover, no low-angle boundaries can be observed in the coarsened ferrite grains (Figure 9(h)). Meanwhile, the amount and size of the carbide clusters increase, and the carbide appears as a network distributed along the ferrite grain boundaries (Figures $9(\mathrm{~h})$ and 9(i)). The results are similar to the results of the SEM and TEM analysis (Figures 7 and 8).

\section{Discussion}

From the results stated above, the weld metals as-welded microstructures for the X80 heavy-wall hot bends are the predominant acicular ferrite (Figure 2(a)). The acicular ferrite in the weld metal is considered as an optimal microstructure to remarkably improve the impact toughness because the overlapping acicular ferrite can inhibit the crack propagation and increase the crack growth path $[8,18]$. Accordingly, the Mn-Mo-Ti-B weld wires are applied to pipeline steel pipes to increase the fraction of acicular ferrite [8]. In doing so, the nonmetallic Ti-oxide inclusion particles work as effective nuclei for the acicular ferrite which exists in the weld metals. Successively, the Ti-oxide inclusion particles can still act as effective nuclei to promote acicular ferrite transformation during the hot bending and cooling processes (Figures 4(a) and 4(b)), and the dominant acicular ferrites are obtained in the weld metal of the hot beds (Figures 2(b)-2(d)). Obviously, the alloy elements have a significant effect on acicular ferrite transformation $[8,18]$. According to the results in Table 1 and Figure 2, the effect of $\mathrm{Ni}$ on the acicular ferrite transformation behavior is noteworthy. The increase of $\mathrm{Ni}$ content in weld metals facilitates the acicular ferrite transformation, refines the final microstructure (Figure 2) [15], and then improves the impact toughness.

The acicular ferrite transformation is thought of as a noncomplete phase transformation and transforms in the temperature range between slightly below polygonal ferrite and slightly over bainite transformation $[8,18]$, and thus, some M/A constituents usually exist between the acicular ferrites, as shown in Figure 4(c). In this work, the starting phase transformation temperatures of the three weld metals determined by dilatometry during the cooling process are $653-519^{\circ} \mathrm{C}, 647-527^{\circ} \mathrm{C}$, and $612-496^{\circ} \mathrm{C}$ for the three weld metals, respectively. The high transformation temperature of the acicular ferrite results that the acicular ferrite microstructure possesses excellent tempering resistance $[19,20]$. The microstructures still maintain the characteristic of 


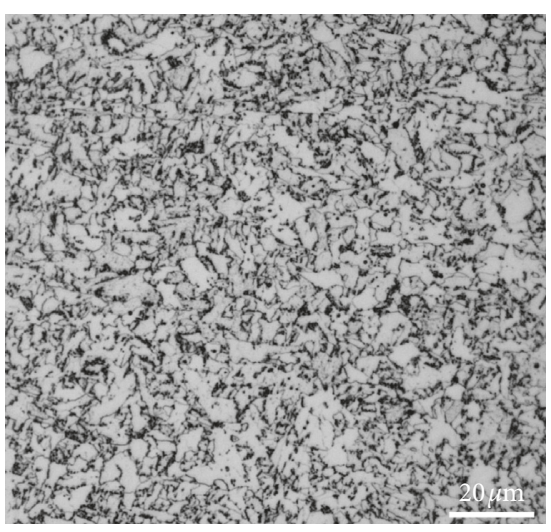

(a)

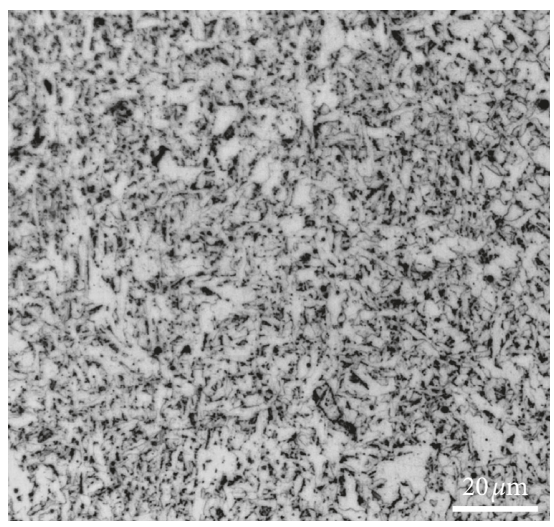

(d)

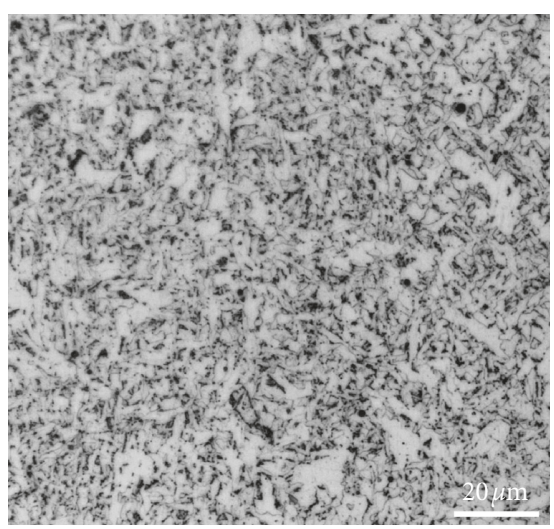

(g)

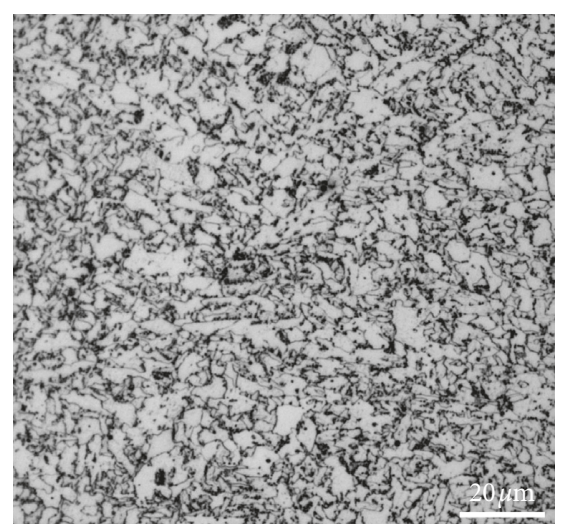

(b)

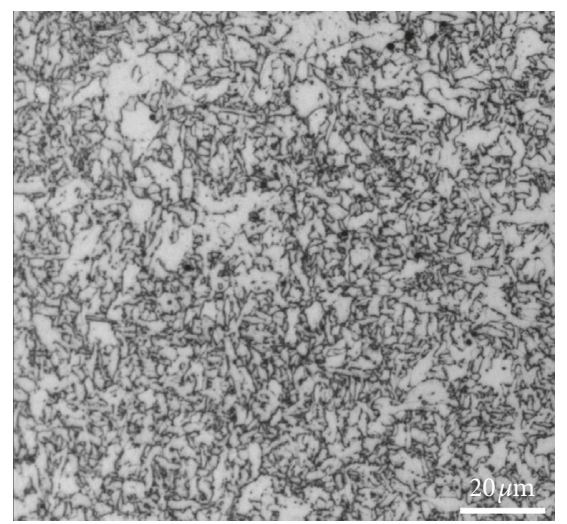

(e)

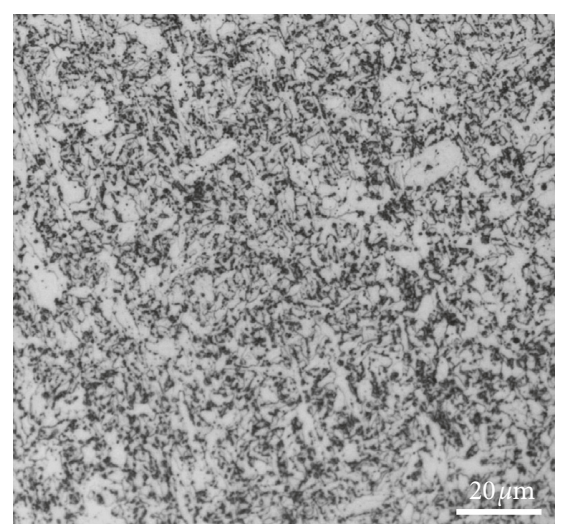

(h)

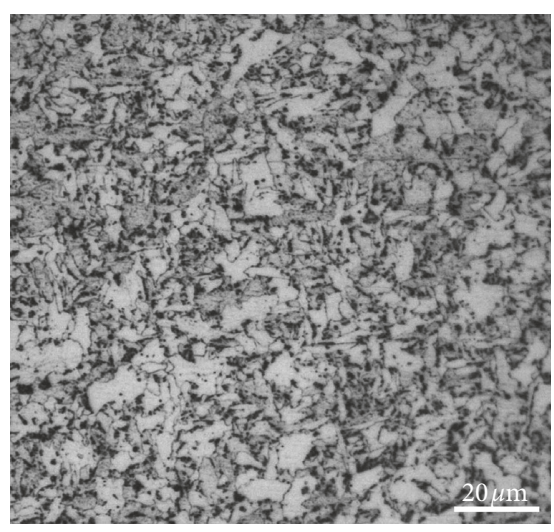

(c)

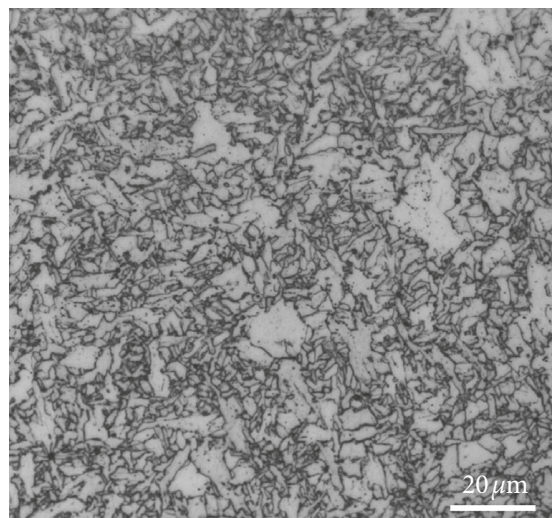

(f)

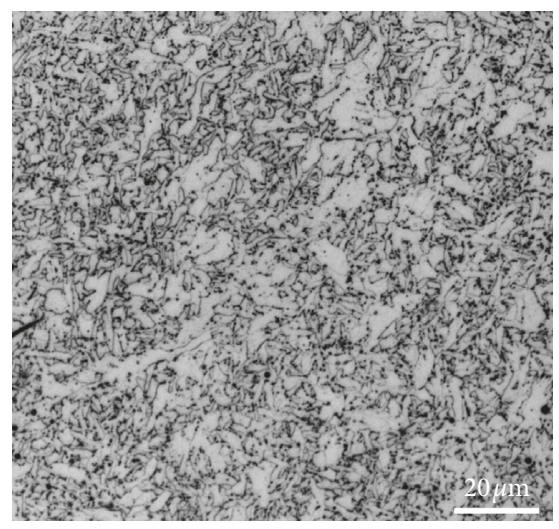

(i)

Figure 6: Optical microstructures of the weld metals tempered at different temperatures. Bend A: (a) $480^{\circ} \mathrm{C}$; (b) $550^{\circ} \mathrm{C}$; (c) $600^{\circ} \mathrm{C}$. Bend $\mathrm{B}$ : (d) $550^{\circ} \mathrm{C}$; (e) $620^{\circ} \mathrm{C}$; (f) $680^{\circ} \mathrm{C}$. Bend C: (g) $550^{\circ} \mathrm{C}$; (h) $620^{\circ} \mathrm{C}$; (i) $680^{\circ} \mathrm{C}$.

acicular ferrite after tempering (Figure 6). Therefore, the changes of acicular ferrite do not fundamentally affect the mechanical properties after the tempering. Nevertheless, the acicular ferrite generally accompanies the M/A constituents transformed at the lower temperature during the tempering process (Figures 2 and 4(c)), as a result, which possess a weak tempering resistance. During tempering, the evolution of $\mathrm{M} /$ A constituents during tempering becomes one of the most important factors influencing the impact toughness.

The M/A constituents are generally regarded as a brittle phase [21], and tempering will weaken the embrittlement effect of the M/A constituents [22]. Hence, the impact energy of the weld metal of hot bends increases after tempering at the low temperature. However, as the tempering temperature increases, the $\mathrm{M} / \mathrm{A}$ constituents begin to degenerate. The degenerated $\mathrm{M} / \mathrm{A}$ constituents decompose into ferrite and carbide particles, and the carbide particles appear in sheet-like or rod-like shapes and mainly distribute at the prior M/A island grain boundaries, i.e., acicular ferrite grain boundaries (Figures 7 and 8). The network carbides along the grain boundaries are accompanied with a decrease of impact toughness $[23,24]$. In doing so, the impact toughness 


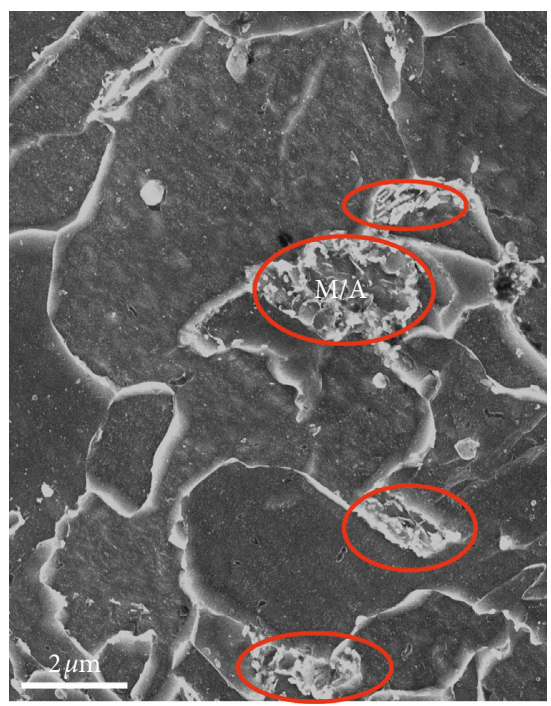

(a)

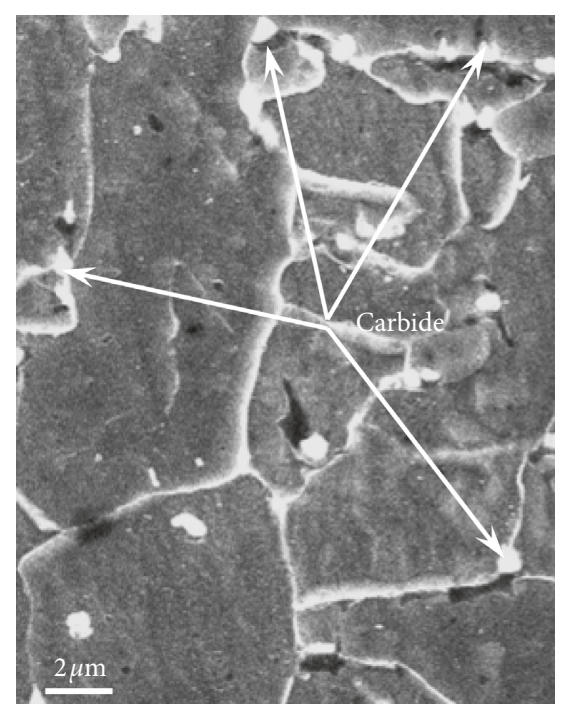

(b)

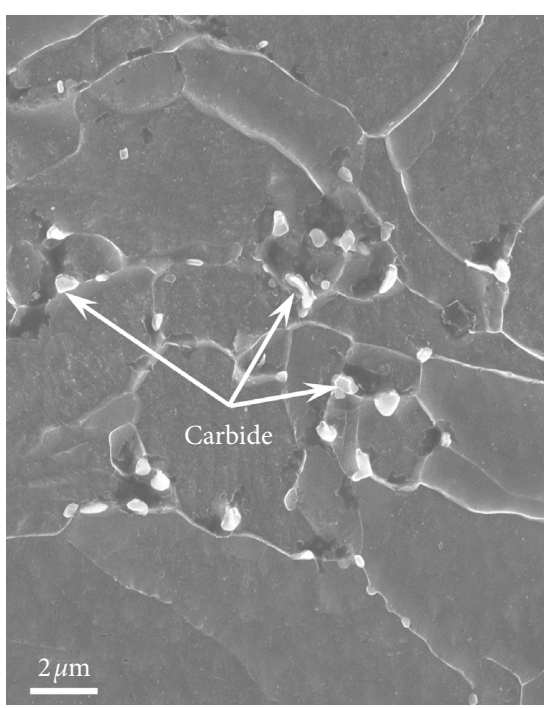

(c)

FIgUre 7: SEM micrographs of Bend C tempered at different temperatures: (a) $550^{\circ} \mathrm{C}$; (b) $620^{\circ} \mathrm{C}$; (c) $680^{\circ} \mathrm{C}$.

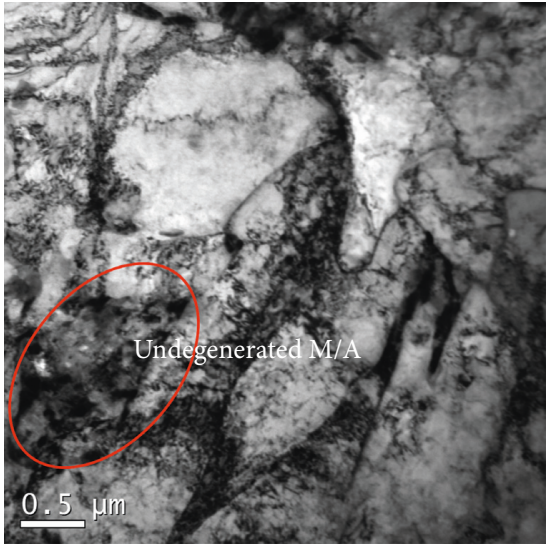

(a)

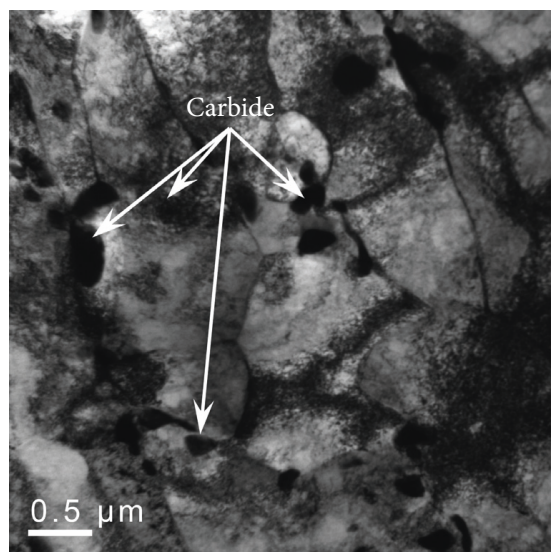

(d)

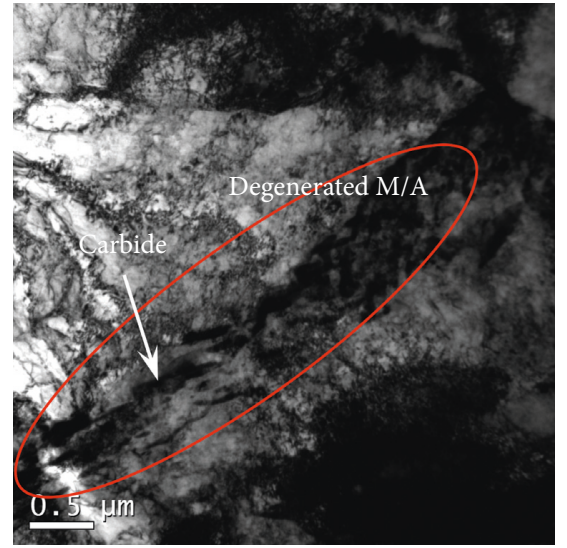

(b)

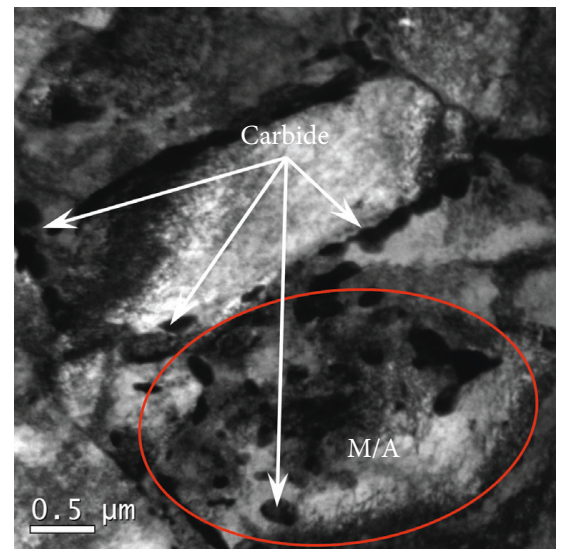

(e)

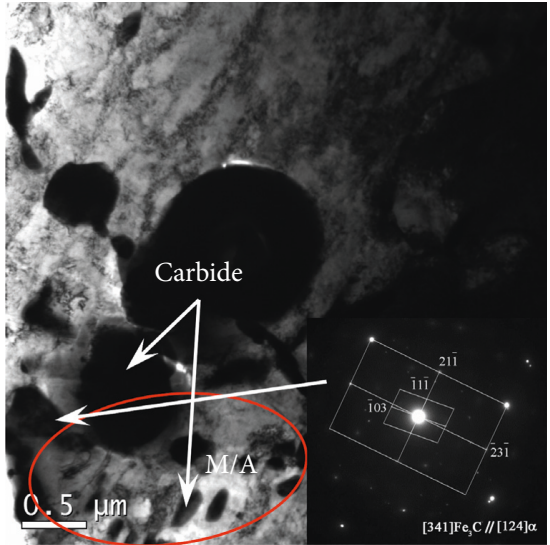

(c)

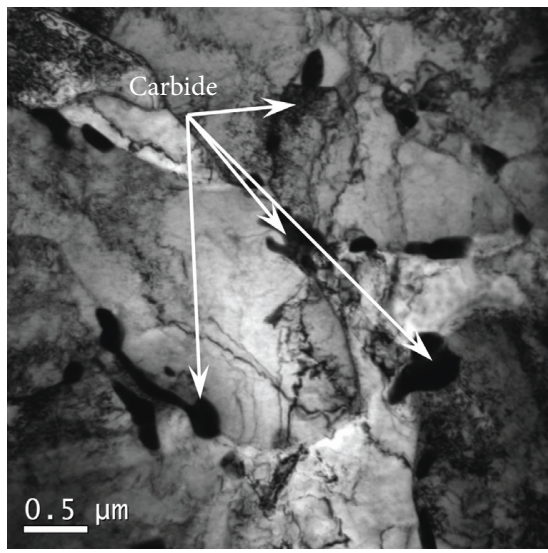

(f)

Figure 8: TEM micrographs of Bend $\mathrm{C}$ tempered at different temperatures: $(\mathrm{a}, \mathrm{b}) 550^{\circ} \mathrm{C}$; (c, d) $620^{\circ} \mathrm{C}$; $(\mathrm{e}, \mathrm{f}) 680^{\circ} \mathrm{C}$.

decreases (Figure 5). With the further increase of temperature, the acicular ferrite, which is transformed by the shear transformation mechanism below the polygonal ferrite transformation temperature, also begins to degenerate, and some new carbide particles begin to precipitate, which mainly nucleate on acicular ferrite grain boundaries (Figures 7(b) and 8(f)). Simultaneously, some ferrites formed from disintegrated M/A constituents begin to coarsen. As a result, the amount 

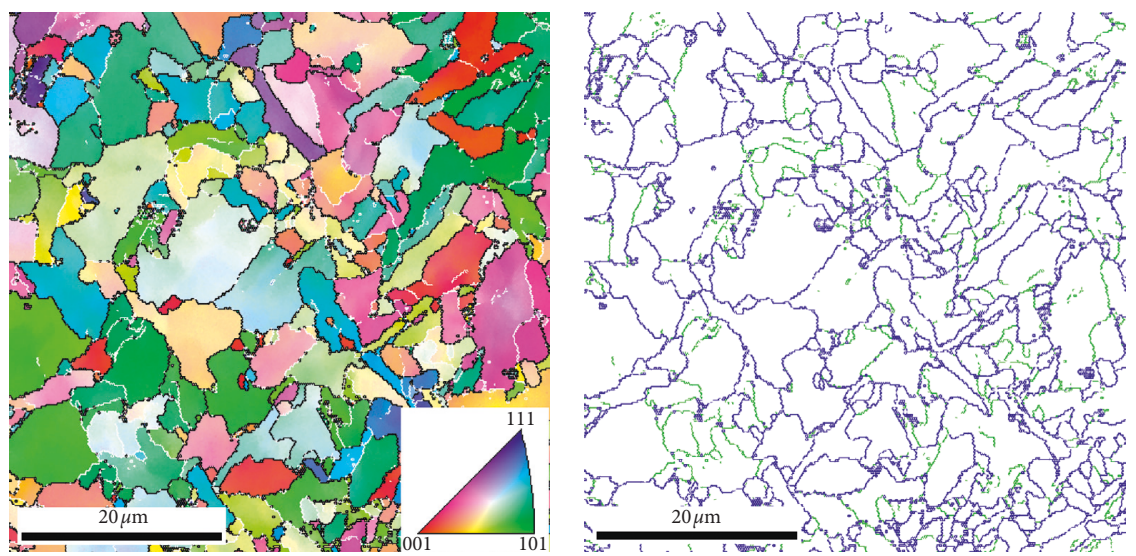

Boundaries: rotation angle

Min Max Fraction

$\begin{array}{lll}2^{\circ} & 15^{\circ} & 0.158\end{array}$

$\begin{array}{lll}15^{\circ} & 180^{\circ} & 0.573\end{array}$

(b)

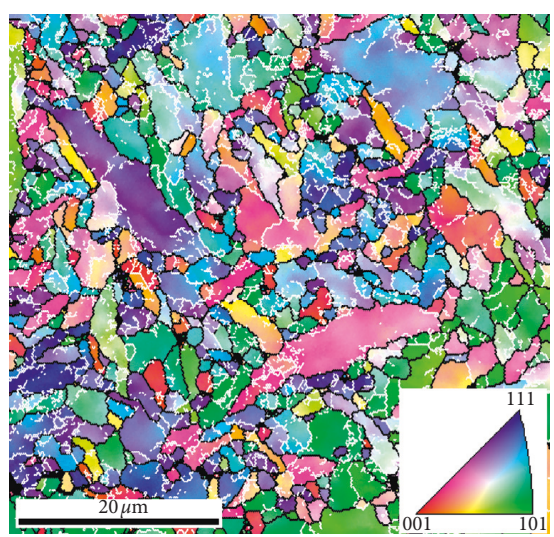

(d)

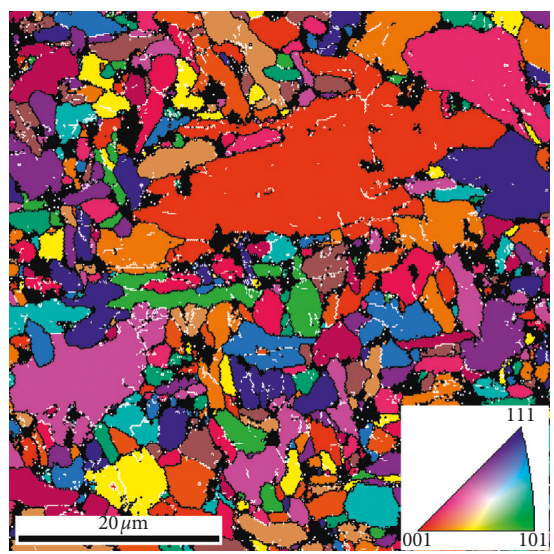

(g)

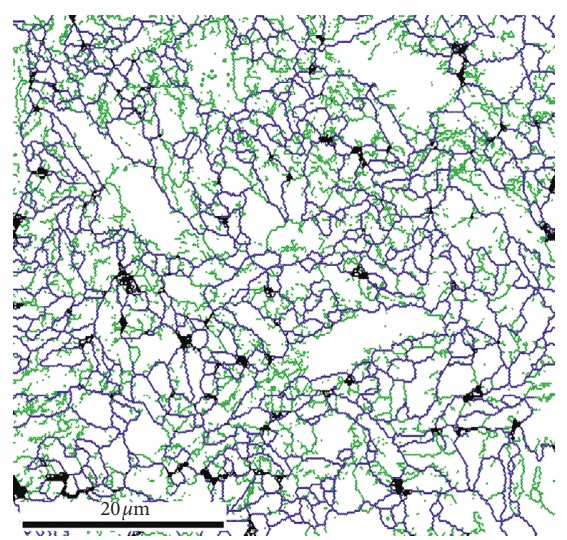

Boundaries: rotation angle Min Max Fraction

- $15^{\circ} \quad 180^{\circ} 0.512$

(e)

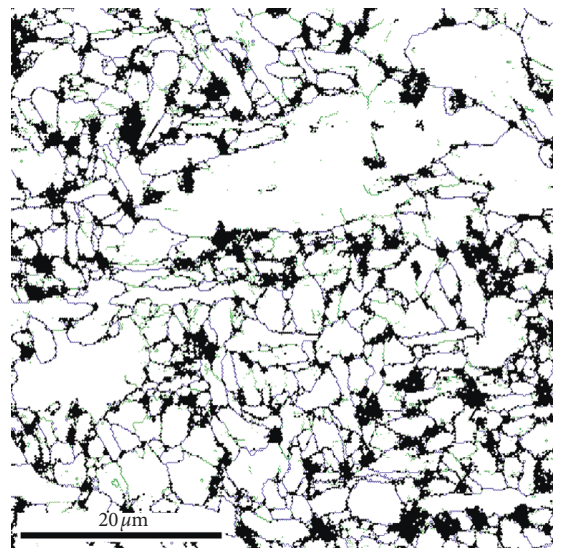

Boundaries: rotation angle Min Max Fraction

$\begin{array}{lll}2^{\circ} & 15^{\circ} & 0.413\end{array}$

$\begin{array}{lll}15^{\circ} & 180^{\circ} & 0.587\end{array}$

(h) $\begin{array}{lll}2^{\circ} & 15^{\circ} & 0.488\end{array}$
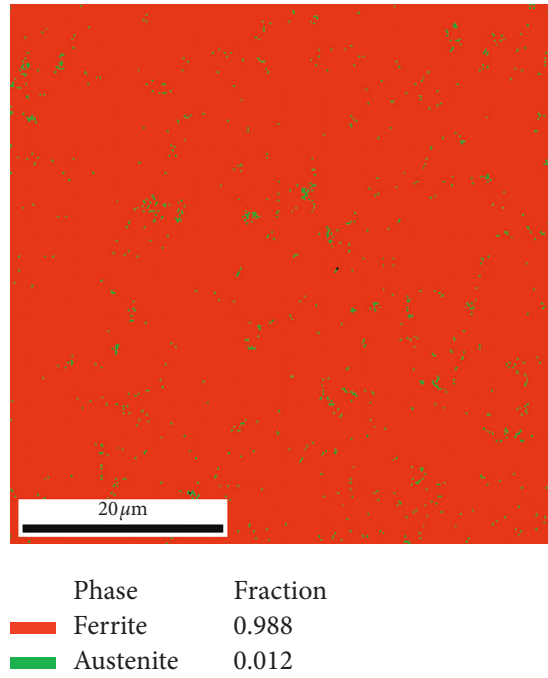

(c)
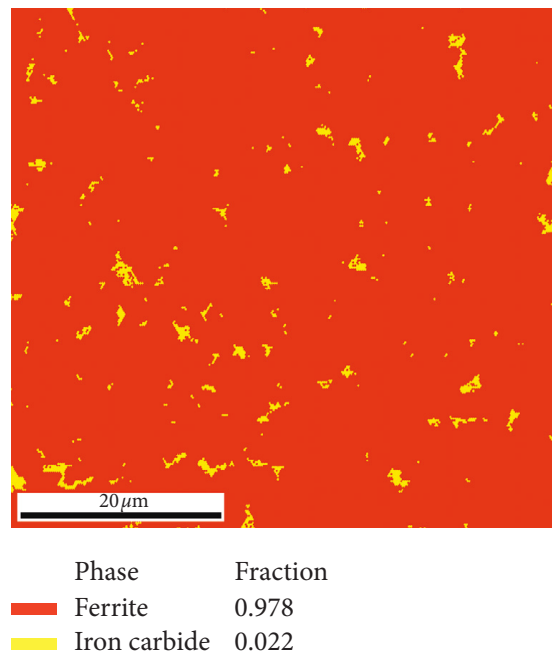

(f)
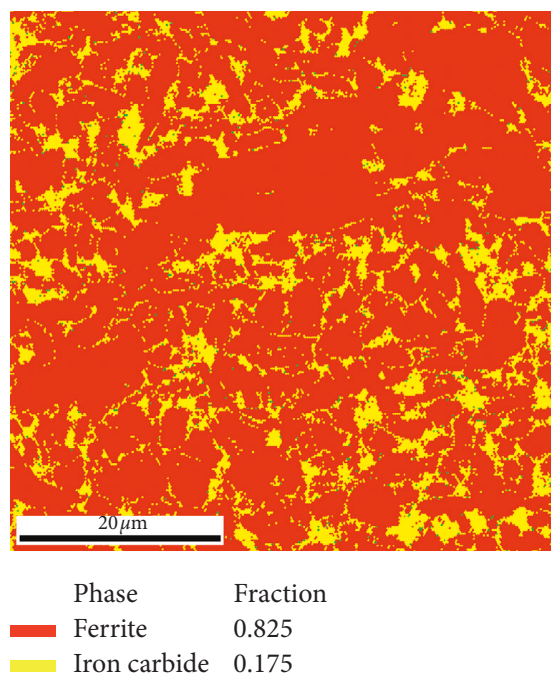

(i)

FIGURE 9: Inverse pole figures and boundary misorientation maps of the ferrite phase and phase distribution maps obtained from EBSD measurement of Bend C after tempering at different temperatures: (a)-(c) $550^{\circ} \mathrm{C}$; (d) $-(\mathrm{f}) 620^{\circ} \mathrm{C}$; (g) $-(\mathrm{i}) 680^{\circ} \mathrm{C}$. 
and size of the carbide particle cluster distributed along ferrite grain boundaries increase (Figure 9(i)); consequently, the impact energy further decreases (Figure 5). From the point of transformation of the carbide particle cluster, refining the acicular ferrite and reducing the size of M/A constituents can be beneficial to reduce the size of carbide particles and its cluster and improve the impact toughness. This is a main reason that the impact energy rises with the increasing $\mathrm{Ni}$ content in weld metals (Figure 5).

According to the above results, the acicular ferrite microstructure and its evolution during tempering play an important role in affecting the impact toughness of the weld metal of the X80 hot bends, especially, the M/A constituents in the acicular ferrite microstructure. The M/A constituents decompose into ferrite and carbide particles during tempering. The carbide particles mainly distribute along ferrite grain boundaries, and the size of carbide particles and carbide clusters increases with the increase of the tempering temperature. As a result, impact toughness decreases with the increase of the tempering temperature. Therefore, refining the acicular ferrite and tempering at a lower temperature reduce the size of M/A constituents and network carbide along ferrite grain boundaries, and the low-temperature impact toughness of the weld metal of X80 hot bends is remarkably improved.

\section{Conclusion}

(1) The acicular ferrite and its change during tempering play an important role in affecting the low-temperature impact toughness, especially, the M/A constituents distributed between the overlapping acicular ferrites. The M/A constituents decompose into needle rod-like carbides during tempering, and the rod-like carbides distributed along the ferrite grain boundary further worsen the low-temperature impact toughness. Hence, the impact energy of the weld metal decreases with the increase of the tempering temperature.

(2) The increase of the Ni content in weld metals can promote the acicular ferrite transformation and refine the acicular ferrite, bainite, and the M/A constituents distributed between the acicular ferrites; furthermore, it can refine the carbide decomposed from the M/A constituent and bainite. Consequently, the adverse influence of the larger size M/A constituents and carbide on the impact toughness is reduced. Thus, the low-temperature impact toughness is improved.

\section{Data Availability}

No data were used to support this study.

\section{Conflicts of Interest}

The authors declare that there are no conflicts of interest regarding the publication of this paper.

\section{Authors' Contributions}

Gui-ying Qiao, Xiu-lin Han, Xiao-wei Chen, and Xu Wang designed the research and conducted the experiments. Guiying Qiao prepared the draft manuscript. Bo Liao and Furen Xiao supervised the project and participated in the discussions. Bo Liao and Fu-ren Xiao revised the manuscript. All authors reviewed the manuscript.

\section{Acknowledgments}

This work was financially supported by the National Natural Science Foundation of China (51671164).

\section{References}

[1] G. Z. Batista, L. Naschpitz, E. Hippert Jr., and I. D. S. Bott, "Induction hot bending and heat treatment of 20" API 5L X80 pipe," in Proceedings of the ASME International Pipeline Conference, IPC (PART A), vol. 3, pp. 89-98, Calgary, Alberta, Canada, September 2006.

[2] A. Mannucci, E. Anelli, F. Zana et al., "Bends for critical line pipe projects: advantages of the off-line full quenching and tempering," in Proceedings of the International Conference on Offshore Mechanics and Arctic Engineering, vol. 6, pp. 175185, Honolulu, HI, USA, May-June 2009.

[3] G. Y. Qiao, X. W. Chen, Z. E. Zhang et al., "Mechanical properties of high-Nb X80 steel weld pipes for the second west-to-east gas transmission pipeline project," Advances in Materials Science and Engineering, vol. 2017, Article ID 7409873, 13 pages, 2017.

[4] W. W. Zhang, H. Li, Q. Chi et al., "Technical specifications for X80 OD $1422 \mathrm{~mm}$ line pipes and corresponding products," Natural Gas Industry B, vol. 3, no. 5, pp. 485-492, 2016, in Chinese.

[5] R. A. Silva, G. Z. Batista, L. F. G. De Souza, and I. S. Bott, "Effect of varying high frequency induction bending on the longitudinal SAW weld of API X80 steel pipe," Materials Science Forum, vol. 706-709, pp. 2059-2065, 2012.

[6] X. L. Zhang and J. X. Liu, "The study on the orderliness of change of microstructure and mechanical properties in simulating the heating process of bending of X80 pipeline steels," Advanced Materials Research, vol. 476-478, pp. 174178, 2012.

[7] X. Wang, F.-R. Xiao, Y.-H. Fu, X.-W. Chen, and B. Liao, "Material development for grade X80 heavy-wall hot induction bends," Materials Science and Engineering: A, vol. 530, pp. 539-547, 2011.

[8] D. Ren, F. R. Xiao, P. Tian, X. Wang, and B. Liao, "Effects of welding wire composition and welding process on the weld metal toughness of submerged arc welded pipeline steel," International Journal of Minerals, Metallurgy and Materials, vol. 16, no. 1, pp. 65-70, 2009.

[9] A. S. Oryshchenko, A. V. Pimenov, S. I. Shekin, and M. G. Sharapov, "The effect of non-metallic inclusions on the toughness of the weld metal of cold-resistant steels at low temperatures," Welding International, vol. 27, no. 9, pp. 681-686, 2013.

[10] M.-C. Zhao, T. Hanamura, H. Qiu, K. Nagai, Y.-Y. Shan, and $\mathrm{K}$. Yang, "Difference in the role of non-quench aging on mechanical properties between acicular ferrite and ferritepearlite pipeline steels," ISIJ International, vol. 45, no. 1, pp. 116-120, 2005. 
[11] R. R. Osmanli and M. Hakem, "Effects of welding and the PWHT on the mechanical properties of API 5L GrX70 steel," Welding in the World, vol. 49, no. 9, pp. 535-539, 2005.

[12] M. Divya, C. R. Das, V. Ramasubbu, S. K. Albert, and A. K. Bhaduri, "Improving 410NiMo weld metal toughness by PWHT," Journal of Materials Processing Technology, vol. 211, no. 12, pp. 2032-2038, 2011.

[13] X. Wang, B. Liao, D.-Y. Wu, X.-L. Han, Y.-S. Zhang, and F.-R. Xiao, "Effects of hot bending parameters on microstructure and mechanical properties of weld metal for X80 hot bends," Journal of Iron and Steel Research International, vol. 21, no. 12, pp. 1129-1135, 2014.

[14] S. Slater and R. Wilkinson, "Investigation into the effect of post weld heat treatment on thermo-mechanically controlled rolled pipeline steels," in Proceedings of the Biennial International Pipeline Conference, IPC, vol. 3, pp. 679-689, Calgary, Alberta, Canada, September 2012.

[15] B. Y. Kang, H. J. Kim, and S. K. Hwang, "Effect of Mn and Ni on the variation of the microstructure and mechanical properties of low-carbon weld metals," ISIJ International, vol. 40 , no. 12 , pp. 1237-1245, 2000.

[16] J. M. Gregg and H. K. D. H. Bhadeshia, "Solid-state nucleation of acicular ferrite on minerals added to molten steel," Acta Materialia, vol. 45, no. 2, pp. 739-748, 1997.

[17] J. Zachrisson, J. Börjesson, and L. Karlsson, "Role of inclusions in formation of high strength steel weld metal microstructures," Science and Technology of Welding and Joining, vol. 18, no. 7, pp. 603-609, 2013.

[18] T. Pan, Z.-G. Yang, C. Zhang, B.-Z. Bai, and H.-S. Fang, "Kinetics and mechanisms of intragranular ferrite nucleation on non-metallic inclusions in low carbon steels," Materials Science and Engineering: A, vol. 438-440, pp. 1128-1132, 2006.

[19] Y. M. Kim, H. Lee, N. J. Kim, and J. Y. Yoo, "Microstructural characteristics of acicular ferrite in linepipe steels," in Proceedings of the International Offshore and Polar Engineering Conference, pp. 19-24, Seoul, South Korea, June 2005.

[20] Y. M. Kim, H. Lee, and N. J. Kim, “Transformation behavior and microstructural characteristics of acicular ferrite in linepipe steels," Materials Science and Engineering A, vol. 478, no. 1-2, pp. 361-370, 2008.

[21] S. Suzuki, T. Kamo, and Y. Komizo, "Influence of martensitic islands on fracture behaviour of high heat input weld HAZ," Welding International, vol. 23, no. 6, pp. 397-402, 2009.

[22] L. C. S. de Araújo, L. C. Cândido, V. B. Trindade, and R. R. Porcaro, "Evaluation of the influence of post welding heat treatments on microstructure and mechanical properties of API 5L X70Q weld joints," Welding International, vol. 31, no. 4, pp. 251-258, 2017.

[23] B. E. Peddle and C. A. Pickles, "Carbide development in the heat affected zone of tempered and post-weld heat treated 2.25Cr-1Mo steel weldments," Canadian Metallurgical Quarterly, vol. 40, no. 1, pp. 105-125, 2001.

[24] A. N. Makovetskii and D. A. Mirzaev, "Effect of a heat treatment on the cold resistance of steels for oil pipelines," The Physics of Metals and Metallography, vol. 110, no. 4, pp. 398-404, 2010. 


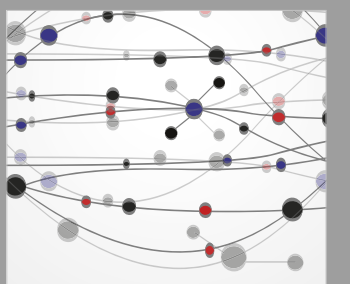

The Scientific World Journal
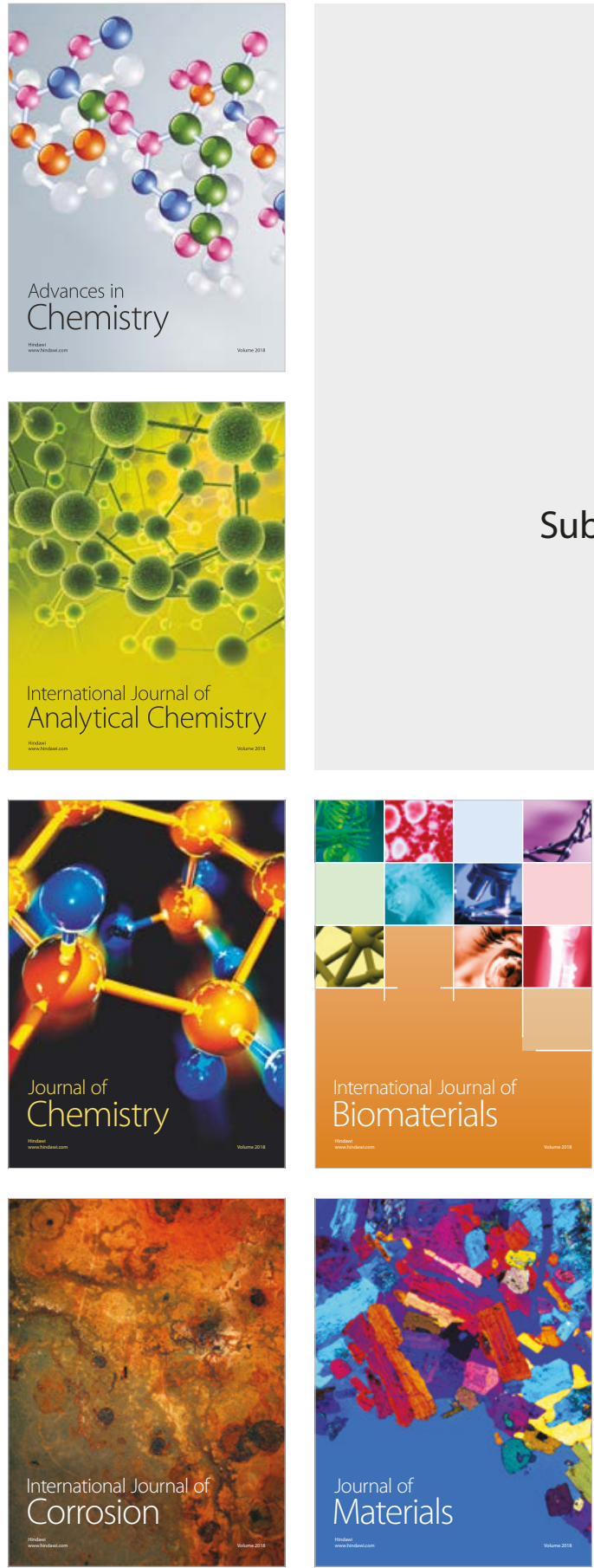

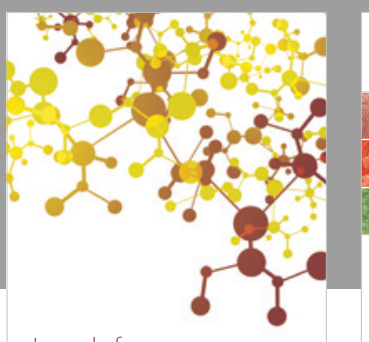

Journal of

Applied Chemistry
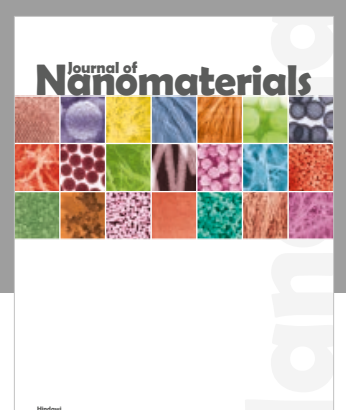

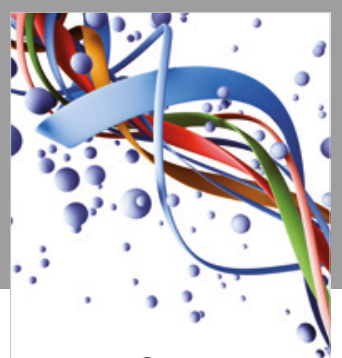

Scientifica

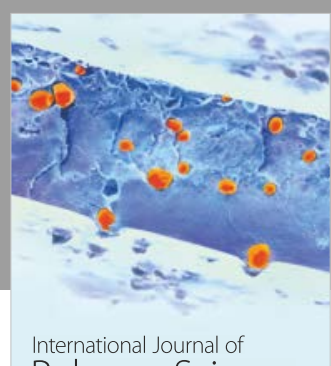

Polymer Science

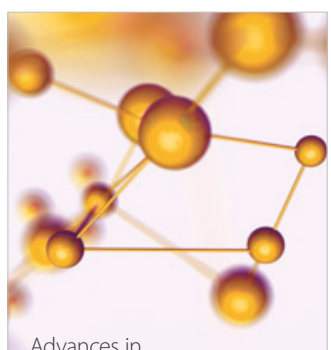

Physical Chemistry
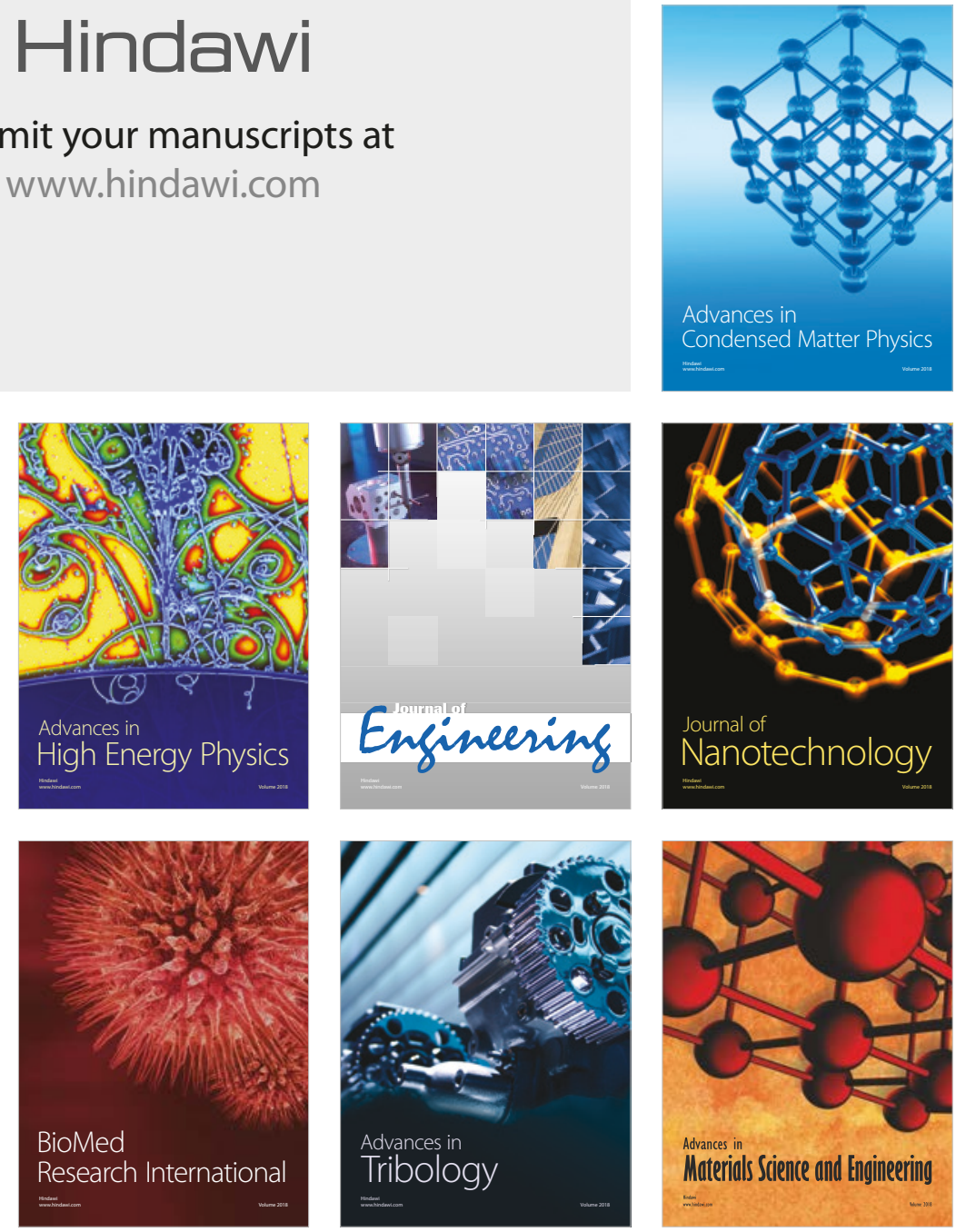